\title{
Likeness and Likeliness Exploring Multidimensional Classification for the Multiverse of Information
}

\author{
Charles van den Heuvel \\ Huygens Institute for the History of the \\ Netherlands \\ Royal Netherlands Academy of Arts and Sciences \\ Prins Willem-Alexanderhof 5 \\ 2509 LT Den Haag \\ Netherlands \\ charles.van.den.heuvel@huygens.knaw.nl
}

\author{
Richard P. Smiraglia \\ School of Information Studies, \\ University of Wisconsin, Milwaukee, \\ Bolton Hall 510 \\ Milwaukee (WI) 53201-0413 \\ USA \\ smiragli@uwm.edu
}

\begin{abstract}
In previous studies grouped under the common denominator "Idea Collider," the CERN Hadron-Collider was used as a metaphor to explore the meaning of breaking down existing structured and less-structured clusters of information into the finest particles to get a better understanding of the laws and nature of the universe of knowledge (Heuvel \& Smiraglia, 2010). Moreover we compared past conceptualizations and visualizations of multidimensional classifications, in particular of faceted systems, and tried to assess their potential for future information retrieval (Heuvel 2011; Heuvel \& Akdag Salah, 2011).

Where most classification theories focused on knowledge integration in a single universe of knowledge, we outlined the framework of an elementary theory of knowledge interaction in a multiverse of knowledge (Smiraglia, Heuvel \& Dousa 2011). We believe that similar to the real universe, not only matter, but also energy and gravitational forces are of importance for understanding the multiverse of information better. For that reason we want to elaborate on the question of how one perceives and interacts with knowledge production.

"Likeness" has been a recurrent theme in classification theory. Here the focus is on the concept "likeliness" which we, unlike Hjørland (2008)], do not describe in the terms of
\end{abstract}

This is the space reserved for copyright notices.

Advances in Classification Research, 2012, October 26, 2012, Baltimore, MD, USA.

Copyright notice continues right here.
Richardson and Bliss as "putting together of like things, likeness" or "alike", but rather refer to as the probability that a meaningful relationship or pattern will be recognized at a certain moment (event). We assume that the likeliness that knowledge "interacts" is conditioned by cognitive and cultural forces of perception. Vertical and horizontal lines might be considered universally as dividers and connectors, but the way we read ascending or descending steps is culturally defined by differences in reading and writing practices. (see Figure 1)

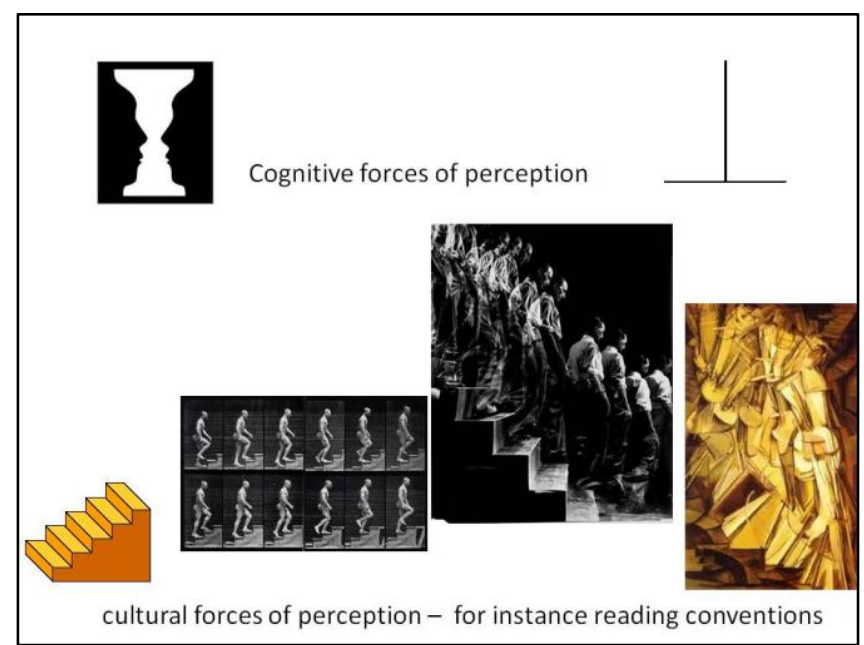

Figure 1 Cognitive and cultural forces of perception

In order to put our still very abstract elementary theory of knowledge interaction to the test we are in need of empirical research. In this lightning paper examples will be shown from art history, musical notation and literature that are more or less likely to interact. (see Figures 2 and 3) 


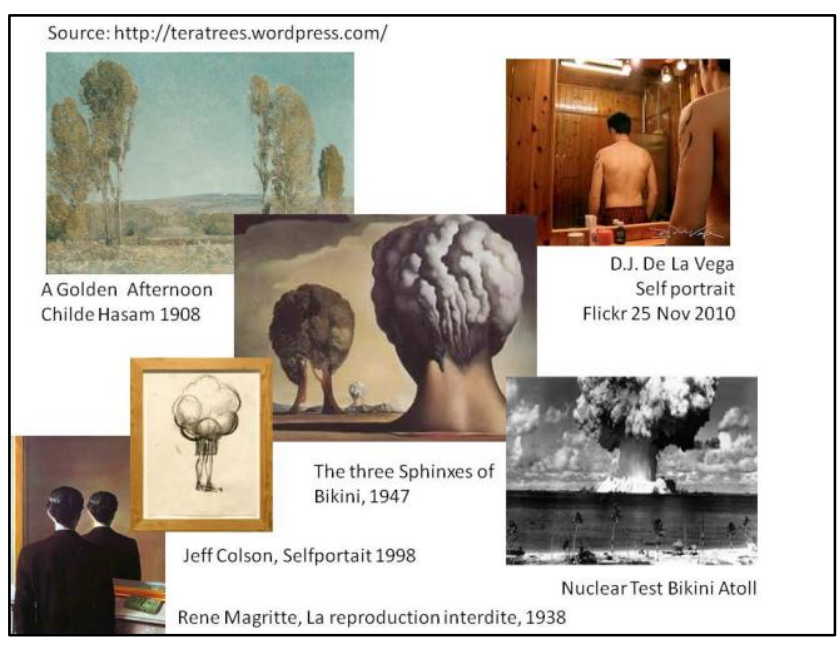

Figure 2 Lines of vision connecting works with similar features through Dali's The three Sphinxes of Bikini

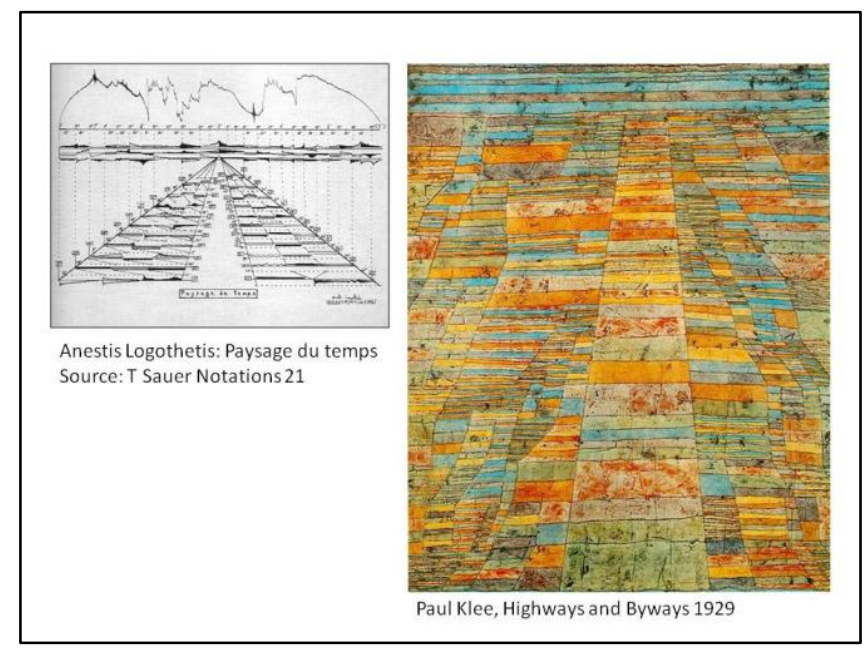

Figure 3 Visual similarities between musical notation of Paysage du temps of Anestis Logothetis and Paul Klee's painting Highways and Byways

In the future we will continue with our Idea Collider experiment and explore the implications of multidimensional classification for information retrieval further in two ways: empirically and theoretically.

The empirical research will build upon the (analysis of) two types of experiments with multi-modal non-semantic information retrieval. The first type consists of experiments with search engines that query for "alike" structural features of multimedia expressions such as color, composition (compare IBM-QBIC), but also rhythm, texture etc. In a recent experiment at Lawrence Technological University, 994 paintings of 34 artists of various art historical styles such as Renaissance, Mannerism, Baroque, Rococo, Romanticism, Impressionism, Expressionism, Surrealism, Fauvism and Abstract Expressionism were compared by automatic computer analysis for form, color and texture. The pattern recognition algorithms were able to measure and quantify visual similarities between paintings, painters, and schools of art and reproduced results in agreement with the analyses of styles by art historians. (see Figure 4) (Shamir \& Tarakhovsky, 2012)

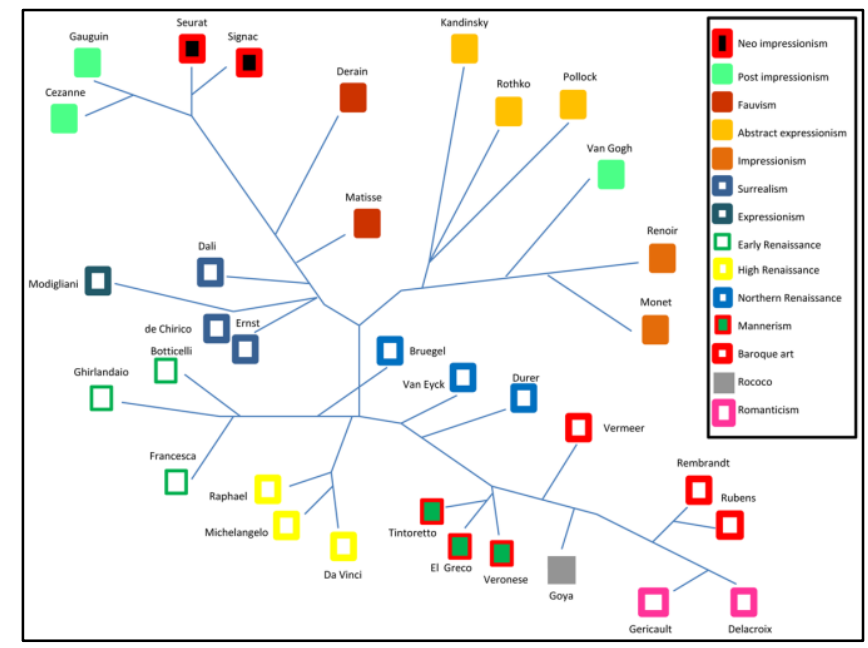

Figure 4 Shamir\&Tarakovsky, Phylogeny of Automatic Computer Analysis of Artistic Styles of Painters

The research of such experiments focuses on the concept of "likeness." The second type of experiment is based on collaborative filtering technology that allow for the deconstruction of various expressions of multi-media. An example is the Art.Similarities experiment (G.J Nauta 2008) which uses a custom-made interface to record visual behavior: the non-verbally expressed visual similarity associations and judgments of distributed individuals which can be assessed both according to human analysis and statistical procedures. This research focuses on the concept of "likeliness."(see Figure 5)

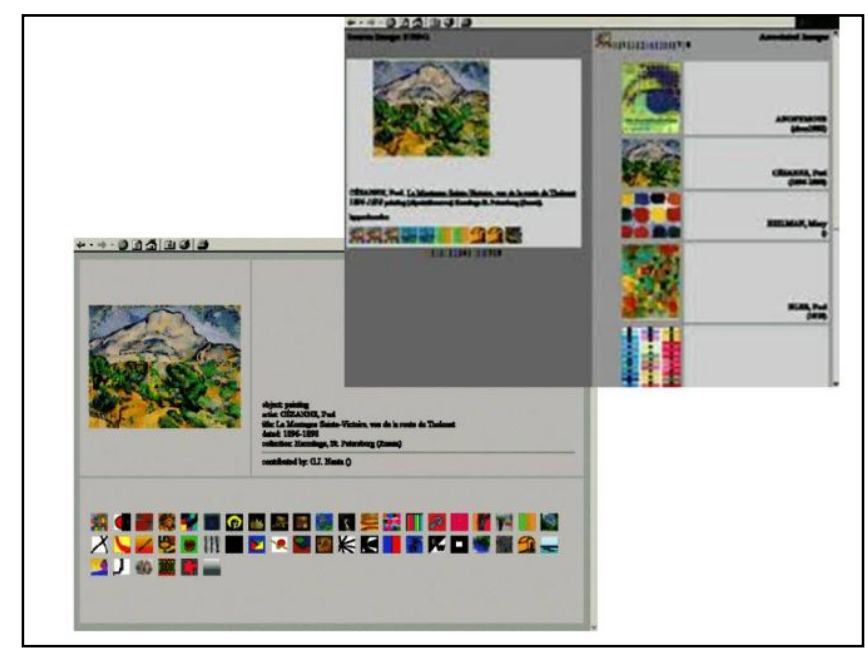

Figure 5 G. Nauta, Interface to record visual assocations Art Similarities - Collaborative Visual Filtering 
Furthermore, we will continue our formulation of an elementary theory of knowledge interaction in a multiverse of knowledge. So far, we individuated the components of such a theory derived from epistemology, semiotic theory and phenomenology. We stressed the importance of creating temporary interfaces to knowledge interaction and stated that they can be described in terms of instantiation and event-ontologies (Heuvel \& Smiraglia 2010; Heuvel 2012 forthcoming). We challenged the universe of knowledge metaphor, but our multiverse of knowledge is still a metaphor. To see whether we can go beyond the metaphor, our next step will be to look into the theory of transdisciplinarity of the Romanian astro-physicist Basarab Nicolescu. Transdisciplinarity in his view not only solves the problem of reduction of multidimensional knowledge, but also provides an explanation for the dynamics, that is for the interactions, within a discontinuous (knowledge) universe that is compliant to the laws of quantum physics. (see Figure 6)

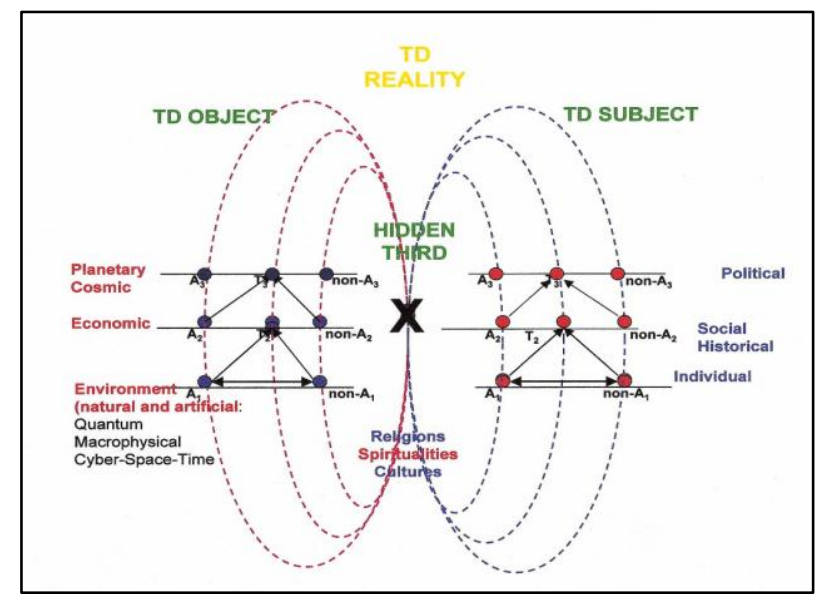

Figure 6 Nicolescu Transdisciplinarity Ontology of Levels of Reality and Hidden Third

\section{Keywords}

Classification theory, Universe of Knowledge metaphor, Multi dimensional classification, Non semantic information retrieval, Transdisciplinarity

\section{REFERENCES}

Heuvel, C., van den \& Smiraglia, R.P. (2010). Concepts as particles: metaphors for the universe of knowledge. In C. Gnoli, Claudio \& F. Mazzochi (Eds.), Paradigms and conceptual systems in knowledge organization, Proceedings of the 11th International ISKO Conference,
23--26 February 2010, Rome, Italy. Advances in Knowledge Organization v. 12 pp. 50--56. Würzburg: Ergon Verlag.

Heuvel, C. van den (2011). Multidimensional classifications: past and future conceptualizations and visualizations. In R.P. Smiraglia, (Ed.) Proceedings from North American Symposium on Knowledge Organization, Vol. 3. (pp. 105-121) Toronto. Retrieved October 1, 2012 from

http://journals.lib.washington.edu/index.php/nasko/article /view/12795

Heuvel, C. van den \& Akdag Salah. A. (2011. Visualizing universes of knowledge: designs and visual analysis of the UDC. Poster. In A Slavic, Aïda \& E. Civallero, (Eds.), Classification \& ontology: formal approaches and access to knowledge: Proceedings of the International UDC Seminar 19..20 September 2011, The Hague, Netherlands. , (pp. 283-294) Würzburg: Ergon Verlag.

Heuvel, C. van den (2012 forthcoming). Multidimensional classifications: past and future conceptualizations and visualizations, Knowledge Organization

Hjørland, B. (2008). Likeliness in knowledge organization (KO). Retrieved October 1, 2012 from: http://www.iva.dk/bh/lifeboat_ko/CONCEPTS/likeliness in_knowledge organiza.htm

Nauta, G.J. (2008). As You Can See: Applying Visual Collaborative Filtering to Works of Art, Digital Humanities Quarterly (2) 1 Retrieved October 12012 from:

http://www.digitalhumanities.org/dhq/vol/002/1/000019/ 000019.html

Shamir, L. \& Tarakhovsky, J.A, (2012). Computer Analysis of Art. ACM Journal on Computing and Cultural Heritage (5) 2, 7 (July)

Smiraglia, R.P., Heuvel, C. van den \& Dousa, T., (2011). Interactions between elementary structures in universes of knowledge. In A. Slavic, \& E. Civallero, (Eds.), Classification \& ontology: formal approaches and access to knowledge: Proceedings of the International UDC Seminar 19--20 September 2011, The Hague, Netherlands. (pp. 25--40) Würzburg: Ergon Verlag,. 